Anales de Geografía de la Universidad Complutense ISSN: 0211-9803

http://dx.doi.org/10.5209/AGUC.66945

\title{
La construcción de la ciudad burguesa en las villas asturianas. Los casos de Llanes y Ribadesella
}

\author{
Héctor Rato Martín ; Gaspar Fernández Cuesta ${ }^{2}$ \\ Recibido: 6 de noviembre del 2018 / Enviado a evaluar: 29 de enero del 2019/ Aceptado: 17 de octubre del 2019
}

Resumen. La Desde mediados del siglo XIX las ciudades españolas comenzaron a experimentar cambios importantes impulsados por la industrialización y la construcción del estado liberal. Cambios que buscaban la adaptación de las tramas heredadas a los gustos y necesidades de la nueva sociedad que se estaba gestando, para la cual se llevaron a cabo obras de reforma interior, pero también la expansión de los planos. En Asturias, el proceso no fue exclusivo de las grandes ciudades; otras menores también participaron de esta renovación, como las antiguas pueblas litorales de origen medieval. Entre estas últimas estaban Llanes y Ribadesella, donde los emigrantes retornados de América promovieron la modernización de la estructura urbana de acuerdo con los principios del urbanismo burgués. A partir de diversas fuentes y de la elaboración de planos, se exponen los casos de estas dos villas, que si bien han seguido a grandes rasgos las pautas generales, presentan ciertas particularidades, tanto compartidas como individuales.

Palabras clave: Ciudad; burguesa; urbanismo; villa; Asturias

\section{[en] The bulding of the "bourgeois city" in the towns of Asturias. The examples of Llanes and Ribadesella}

\begin{abstract}
The Spanish cities started to suffer a big transformation since the middle of the 19th Century as a result of the emergence of the earliest industrial manifestations and the building of the liberal state. This alteration appeared in the adaptation of the inherited centers to the new tastes and needs with internal reform and urban extension projects. In Asturias, like in other regions, the process was not only exclusive of the big towns but other smaller villages also were involved in this renewal, like the entities of population located in the mining areas or the former medieval seaside towns. That was the case of the coastal towns of Llanes and Ribadesella, where, thanks to the returning emigrants from America, there was a significant modernization of the urban structure according to the principles of the new bourgeois urbanism.
\end{abstract}

Keywords: City; bourgeoisie; urban planning; town; Asturias.

1 Departamento de Geografía. Universidad de Oviedo.

E-mail: hector.rato@gmail.com

2 Departamento de Geografía. Universidad de Oviedo.

E-mail: gaspar@uniovi.es 


\section{[fr] La construction de la "ville bourgeoise" en Asturies. Les exemples de Llanes et Ribadesella}

Résumé. A partir du milieu du 19ème siècle les villes espagnoles ont connu des changements substantiels à la suite de l'irruption des plus précoces manifestations industrielles et de la construction de l'État libéral. Ces changements se sont concrétisés essentiellement par l'adaptation des noyaux urbains aux nouveaux goûts et besoins de la nouvelle société au moyen de projets de réaménagement et d'extension urbaine. En Asturias, ce processus ne fut pas exclusif des grandes villes ; d'autres petites agglomerations urbaines ont aussi participé à ce renouvellement, comme certains villages miniers et les anciennes villages littoraux, notamment Llanes et Ribadesella, où les migrants retournés d'Amérique ont promu une significative modernisation de la structure urbaine en accord avec les principes de l'urbanisme bourgeois.

Mots clés: Ville; bourgeoisie; urbanisme; village; Asturias.

Cómo citar. Rato Martín, H. y Ferández Cuesta, G. (2019): La construcción de la ciudad burguesa en las villas asturianas. Los casos de Llanes y Ribadesella. Anales de Geografía de la Universidad Complutense, 39(2), 415-438.

Sumario. 1. Introducción. 2. La construcción de la ciudad burguesa en el contexto asturiano. 3. La construcción del espacio burgués en las villas de Llanes y Ribadesella. 3.1. El emplazamiento marítimo y la utilización de terrenos ganados al mar para organizar la expansión urbana. 3.2. El papel desempeñado por los "indianos" en la construcción del espacio burgués. 3.3. El temprano interés de las corporaciones municipales por aprobar proyectos de ordenación urbana: los proyectos de ensanche y reforma interior. 3.4. Los rasgos diferenciadores de los espacios burgueses de Llanes y Ribadesella. 4. Conclusiones. 5. Bibliografía. 6. Fuentes documentales.

\section{Introducción}

A partir de mediados del siglo XIX, una vez que comenzaron a sentirse los efectos de la industrialización, España inició una profunda transformación de su modelo urbano tradicional. Las ciudades, que habían experimentado pocos cambios desde la Edad Media, comenzaron a alterar sus tramas para adaptarlas a las necesidades de la nueva sociedad industrial. Las calles estrechas y sinuosas, producto del crecimiento orgánico característico del Antiguo Régimen, resultaban inadecuadas para los nuevos tráficos generados por las fábricas y el ferrocarril, además de ser un obstáculo para satisfacer las condiciones de vida que exigía la burguesía emergente (viviendas de mayores dimensiones, mejores condiciones higiénicas, etc.).

Se imponía, pues, la adopción de un nuevo modelo urbano, en cuya construcción desempeñaron un papel fundamental tanto la burguesía como las instituciones surgidas con el estado liberal (Delgado, 1995), especialmente las del poder central, 
que fueron las que adquirieron, a lo largo de la segunda mitad del siglo XIX, las competencias urbanísticas hasta entonces en manos de los ayuntamientos.

Se asiste así al surgimiento de una planificación urbana que, pese a la diversidad de las figuras normativas, se articuló fundamentalmente en torno a las leyes de reforma interior, concebidas para orientar la mejora de la trama heredada, y las leyes de ensanche, con las que se pretendía ordenar el crecimiento de la ciudad.

La primera de las leyes relevantes promulgadas por el Estado sobre reforma interior fue la Real Orden de 25 de julio de 1846, que establecía la obligatoriedad de levantar un plano geométrico en los núcleos urbanos de "crecida población" (Bassols, 1973). En 1859, dada la confusión a la que daba lugar ese término, se promulgó una nueva Real Orden que acotaba la obligación de dotarse de un plano geométrico a las localidades de más de 8.000 habitantes. Pese a ello fueron pocos los ayuntamientos que cumplieron con la normativa, probablemente por razones económicas y por la carencia de profesionales, lo que llevó a promulgar otras leyes que se limitaron a imponer la realización de planos parciales sobre las áreas afectadas por los proyectos de nuevas alineaciones (Bassols, 1973). Fue el caso de la fracasada Ley General de Posada Herrera de 1861 y de la Ley de Reforma Interior de 1895 sobre saneamiento y mejora interior de las poblaciones (Bassols, 1973).

Respecto a la normativa para organizar el crecimiento espacial, lo más destacado fueron las Leyes de Ensanche aprobadas en 1864, 1876 y 1892, a las que se acogieron muchas ciudades para redactar sus proyectos de expansión ${ }^{4}$. En ellas se definían "los deberes de los propietarios del suelo y de la Administración, fórmulas para la cesión de viales, mecanismos de reparcelación o las cargas y beneficios que correspondían a los propietarios del suelo" (Fernández, 2015, 15).

El corpus normativo citado mantuvo su vigencia hasta 1924, año en el que el gobierno de Primo de Rivera promulgó el Estatuto Municipal, un documento que mantuvo buena parte de los contenidos de las leyes anteriores, pero que devolvió las competencias urbanísticas a los municipios. Entre sus principales propuestas se encontraba la de obligar a dotarse de un proyecto de ensanche a los municipios de más de 10.000 habitantes que hubiesen tenido, además, un crecimiento demográfico superior al 20\% durante los últimos 10 años (Reglamentos, 1924).

\footnotetext{
${ }^{3}$ Las escasas atribuciones legislativas en materia urbanística estaban en manos de los ayuntamientos, quienes mediante normas de policía urbana concretaban aspectos de la vida pública, el ornato, la limpieza y la seguridad de las edificaciones. Sin embargo, no definían las alineaciones que debían seguir ni la reforma interior ni el crecimiento exterior. Por otro lado, la descentralización de las competencias urbanísticas provocaba notables diferencias entre localidades, en virtud de su capacidad para adoptar decisiones. Una situación que comenzó a cambiar a partir de la segunda mitad del siglo XVIII, cuando el Estado empezó a centralizar la política urbanística y a promulgar instrucciones para generalizar la aprobación y la correcta aplicación de las ordenanzas municipales (Bassols, 1973).

${ }^{4}$ Las leyes de ensanche, junto con las desamortizadoras, supusieron, en muchas ocasiones, un importante inconveniente para la rápida urbanización de los terrenos sobre los que aquéllos debían desarrollarse. Por eso, en determinadas localidades, los gobiernos municipales prefirieron aprobar soluciones distintas, más sencillas, para regular su crecimiento (Mas, 1999).
} 
La modernización urbana derivada de la aplicación de estas normas dejó su huella, sobre todo, en las principales ciudades, como las nuevas capitales surgidas de la división provincial de Javier de Burgos (1833), las agrociudades de la mitad sur peninsular, o las que comenzaban a despuntar gracias a las incipientes actividades mineras o industriales (Fernández, 2011). Ahora bien, también afectó a las ciudades más pequeñas que aprobaron proyectos de ensanche, sobre todo tras la entrada en vigor del Estatuto de 1924 (Esteban, 1976).

En este artículo, sobre el desarrollo urbano de Llanes y Ribadesella, dos pequeñas villas del litoral oriental asturiano, nuestro objetivo ha sido, precisamente, dejar patente esa modernización y, por supuesto, contribuir a un mejor conocimiento del proceso de formación del espacio burgués en esas villas, un hecho poco conocido hasta el momento.

Para alcanzar este objetivo se han utilizado numerosas fuentes de diversa índole, bibliográficas, archivísticas, cartográficas o fotográficas. Su consulta, análisis y sistematización nos han permitido reconstruir el proceso de formación del espacio burgués en las dos localidades, así como contextualizarlo en el de ámbito nacional.

La documentación archivística ha sido fundamental para conocer de primera mano los proyectos de reforma y ampliación urbana, las licencias de construcción o los libros de actas municipales, las cuales nos han permitido conocer con alto grado de detalle su historia urbana. El estudio de las monografías sobre Llanes y Ribadesella, por su parte, nos ha aportado información de carácter económico, histórico, etc que ha complementado la consulta de las fuentes primarias. Por último, la utilización de cartografía, tanto histórica como reciente, ha resultado decisiva para comprender y explicar la morfología de ambas localidades. A partir de ellas hemos elaborado planos en los que se representan distintos tipos de procesos y fenómenos acaecidos en ambas localidades desde mediados del siglo XIX.

\section{La construcción de la ciudad burguesa en el contexto asturiano}

En Asturias, el desarrollo de las actividades mineras y fabriles a partir de mediados del siglo XIX tuvo importantes consecuencias sobre su sistema urbano (Fernández y Fernández, 1991; Vázquez y Ojeda, 1990), pues la necesidad de mano de obra provocó la llegada de inmigrantes procedentes de otras provincias más atrasadas (Pérez et al., 1983; López, 1992) que, al concentrarse en las áreas más ricas, ejercieron una fuerte presión sobre la vivienda e impulsaron la creación de nuevos espacios residenciales (Alvargonzález, 1977; Fernández, 1982b; Pérez, 1982). De forma simultánea comenzó a formarse, en los núcleos más dinámicos, una burguesía local enriquecida con las nuevas actividades; pero también con otras, como el transporte o el comercio especializado que comenzaba a proliferar estimulado por el aumento general de la renta (Erice, 1994). Esta burguesía pronto comenzó a demandar espacio residencial de calidad, bien dotado de equipamientos, cuya construcción, a través de operaciones de expansión y de cirugía urbana, se constituiría 
a su vez en una nueva forma de negocio y de acumulación de riqueza (Capel, 1975; Mas, 1996)

En Oviedo la capitalidad provincial y, sobre todo, la nueva fábrica de armas se constituyeron en el motor fundamental de su desarrollo demográfico y urbanístico, este último ejecutado, fundamentalmente, mediante parcelaciones particulares (Quirós, 1983; Tomé, 1988). En Gijón y Avilés fueron determinantes sus instalaciones portuarias, pues gracias a ellas se convirtieron en los principales exportadores de la hulla regional y, más tarde, en foco de atracción para inversiones fabriles. Su posterior crecimiento espacial estuvo dirigido por proyectos de ensanche, pero en la primera también fue relevante la participación de la iniciativa privada, que promovió parcelaciones particulares, en ocasiones muy extensas, para construir viviendas destinadas a las clases medias y bajas (Alvargonzález, 1977; Fernández, 2015; Morales, 1983).

En estas tres ciudades también proliferaron las obras de reforma interior, entre ellas las destinadas a derribar las murallas, a rectificar alineaciones y a abrir nuevas calles y plazas. Todas ellas con el fin de mejorar la circulación y favorecer la conexión entre los viejos y los nuevos espacios urbanos.

No menos relevante, al menos en términos relativos, fue el desarrollo urbano de la cuenca hullera central una vez que comenzó a explotarse su riqueza minera y entraron en funcionamiento las fábricas siderúrgicas que la transformaban. En un principio, las aldeas situadas en las laderas, en las que los mineros podían compaginar su actividad principal con la agroganadera, absorbieron parte del crecimiento demográfico (Fernández, 1982a), pero éste comenzó pronto a concentrarse en el fondo de los valles, propiciando así su urbanización; primero, utilizando como ejes directores las carreteras preexistentes y, después, las pautas fijadas por algunos planes de ensanche (Fernández 1980; Fernández, 1982b; Pérez, 1982). El desarrollo de ambas formas de crecimiento, junto a la incorporación de las aldeas primitivas, acabó configurando diversos continuos urbanos de carácter lineal, extendidos a lo largo de los valles del Nalón, Caudal, Aller o Turón (Fernández 1980; Fernández, 1982b; Pérez, 1982), en los que se situaban núcleos como Sama de Langreo, La Felguera, Mieres, Pola de Laviana, Sotrondio, El Entrego o Blimea ${ }^{5}$. Localidades todas ellas que dispusieron, antes o después de la aprobación del Estatuto de 1924, de proyectos de ensanche propios, cuya ocupación, sin embargo, se retrasó durante varias décadas (Fernández 1980; Fernández, 1982b; Pérez, 1982; Fernández y Velasco, 1992; RodríguezFelgueroso, 1993).

Otro ámbito espacial afectado durante esta época por la llegada de las primeras manifestaciones industriales fue el de las villas. Estas acogieron entonces sus

\footnotetext{
${ }^{5}$ La singularidad asturiana de los concejos, en los que pueden coexistir varios núcleos de población de cierto tamaño, propició que algunas corporaciones municipales aprobaran planes de ensanche para más de una localidad. Ocurrió en Langreo y en San Martín del Rey Aurelio, municipios en los que se aprobaron proyectos de este tipo para Sama y La Felguera, y para El Entrego, Sotrondio y Blimea, respectivamente (Fernández, 1980; Suárez, 2000).
} 
primeras fábricas y talleres, al tiempo que revitalizaban su comercio, una de sus actividades básicas tradicionales (Murcia, 1981). Este resurgir económico pronto se trasladó al crecimiento urbano que, en ocasiones, estuvo liderado por la iniciativa privada $^{6}, \mathrm{y}$, en otras, por las directrices de los proyectos de reforma interior y de ensanche aprobados por las corporaciones municipales.

La iniciativa particular abrió calles y dividió parcelas de su propiedad, por lo que generalmente no implicó ni la incorporación de grandes baldíos ni la creación de tramas de la entidad suficiente para dejar su huella en el plano. Es más, en muchos casos se limitó a construir las nuevas edificaciones en las márgenes de las carreteras y los caminos preexistentes. Una situación que provocó la aparición de baldíos en los intersticios entre edificios, especialmente en los lugares más alejados del centro, que más tarde fueron comprados por la burguesía local para erigir en ellos sus residencias, en ocasiones de notable interés histórico y arquitectónico. Como contrapartida, en los tramos más próximos al centro, así como en los solares vacíos del interior de los cascos, la escasez de espacio alentó la construcción de edificios de viviendas múltiples, de tres o cuatro plantas y adosados entre sí, en cuyos bajos se instalaron nuevos comercios especializados destinados a satisfacer, sobre todo, las necesidades de la burguesía emergente. Todo ello provocó una ocupación mucho más densa del espacio. En Vegadeo este tipo de crecimiento fue vertebrado por las carreteras de Galicia, Taramundi y Boal; en Cangas de Onís por las de Covadonga y Castilla; en Villaviciosa por la carretera de la costa, y en Infiesto o Pola de Siero por la de Oviedo a Torrelavega (Murcia, 1983). Consecuencia de este crecimiento orgánico fue una trama viaria irregular, similar a la existente, muy difícil de identificar en el plano actual. Más aún si consideramos que el tamaño de la mayoría de estas actuaciones nunca llegó a suponer una ampliación sustancial del núcleo urbano original.

Las iniciativas municipales, en lo que se refiere a la ejecución de proyectos de reforma interior, también fueron pocas y de escasa entidad, en parte debido a la penuria financiera, por lo que no modificaron en exceso la trama anterior. En consecuencia, a mediados del siglo XX los cascos urbanos de las villas todavía mantenían muchos de sus rasgos históricos. Una de las principales excepciones la constituyeron las villas amuralladas, cuyas defensas fueron derribadas parcial o totalmente para facilitar su expansión. Fue el caso de Navia (Martínez, 1965; Acevedo y Huelves, 1900), Villaviciosa (Pedrayes, 1994) Grado (Fernández de Miranda, 1982) o Pravia ${ }^{7}$.

\footnotetext{
${ }^{6}$ En Villaviciosa, por ejemplo, tras varios intentos municipales de dotarse de un plano de ensanche, fue la iniciativa privada quién, mediante una doble parcelación de baldíos cercanos al casco, lideró la expansión urbana (Pedrayes, 1994). En Luarca, a pesar de la existencia de un plano de ensanche que dirigió parte del crecimiento urbano, los particulares como los "señores Lavandera y Compañía" jugaron un papel muy destacado en la ampliación de la superficie urbanizada merced a la edificación de algunos grupos de viviendas en el entorno del río Negro (Méndez, 1993).

${ }^{7}$ En el caso de Pravia el derribo de la cerca se debió de iniciar en la segunda mitad del siglo XVIII (García, 2013).
} 
Por lo que respecta a los proyectos de ensanche su difusión fue especialmente intensa tras la entrada en vigor del Estatuto Municipal de 1924, pero su posterior grado de ejecución fue muchas veces reducido, bien por la oposición de los propietarios de los terrenos sobre los que deberían extenderse o porque fueron diseñados para organizar un crecimiento urbano que nunca llegó a producirse. En realidad, solo han dejado una huella destacable los planes que, debido a la inacción urbanística de la administración durante la Guerra Civil y el posterior período autárquico, mantuvieron vigentes sus directrices hasta las décadas de 1960 y 1970, lo que favoreció la consolidación de una trama diseñada 50 años antes. Fue el caso del ensanche diseñado por el ingeniero Ildefonso Sánchez del Río para Pola de Siero, aprobado en 1932, que sirvió para organizar el crecimiento de la villa hasta la década de 1970 (Quirós, 1985); o el de Navia, donde buena parte de las alineaciones diseñadas por el ingeniero José Martín Elvira (1934) fueron incorporadas al primer Plan General de Ordenación Urbana de la localidad, aprobado en 1970, y a otras figuras posteriores (Rato y Fernández, 2016). En cualquier caso, el espacio burgués de las villas no llegó a alcanzar, casi nunca, el desarrollo que tuvo en las grandes ciudades.

\section{La construcción del espacio burgués en las villas de Llanes y Ribadesella}

Los espacios burgueses respectivos de Llanes y Ribadesella poseen, además de los rasgos propios de la generalidad de las ciudades españolas, algunas características específicas y comunes a ambos, cuyo origen se encontraría en condicionamientos de carácter local, como el tipo de emplazamiento, el papel desempeñado por los "indianos" en su construcción, o la temprana conciencia urbanística de sus responsables municipales.

\subsection{El emplazamiento marítimo y la utilización de terrenos ganados al mar para organizar la expansión urbana}

La localización de Ribadesella y Llanes en la desembocadura de los ríos Sella y Carrocedo, respectivamente, condicionó, como ocurrió en otras muchas localidades litorales, su evolución histórica posterior. Desde su fundación comenzaron a explotar los recursos pesqueros y a desarrollar el tráfico marítimo, y estas actividades aseguraron su dinamismo y su ventajosa posición en el sistema urbano asturiano durante la Edad Media y buena parte de la Edad Moderna. En contrapartida, su emplazamiento en una estrecha franja de terreno situada entre la línea de costa y las empinadas laderas de los relieves próximos redujo considerablemente las disponibilidades de suelo llano, por lo que, cuando este se hizo necesario, se obtuvo, en muchas ocasiones, ganándoselo al mar. Especial importancia tuvieron, a este respecto, los proyectos aprobados para mejorar las instalaciones portuarias, pues una vez terminadas las obras las villas pudieron disponer de nuevos espacios ganados al mar que posteriormente fueron utilizados, al menos en parte, para expandirse. 
En Llanes las obras públicas realizadas en la desembocadura del río Carrocedo a partir de $1884^{8}$ (canalización del cauce, desecación de marismas, construcción de nuevos diques) sirvieron para obtener suelo llano, que más tarde fue aprovechado para ampliar la superficie de los muelles y facilitar las operaciones de carga y descarga, así como para construir, ya en la década de 1930, la nueva lonja (Del Río, 2011). Mayor incidencia tuvieron, para la expansión urbana, las obras ejecutadas por la iniciativa privada tras la concesión a particulares de los terrenos marismeños situados aguas arriba del puente ${ }^{9}$, pues estos, una vez saneados, se convirtieron en solares que más tarde acogieron nuevas edificaciones ${ }^{10}$, entre ellas el teatro Benavente, emblema de la ciudad burguesa (Fig.1).

Figura 1. Terrenos ganados a la ría del Carrocedo, en Llanes, entre 1884 y 1920.

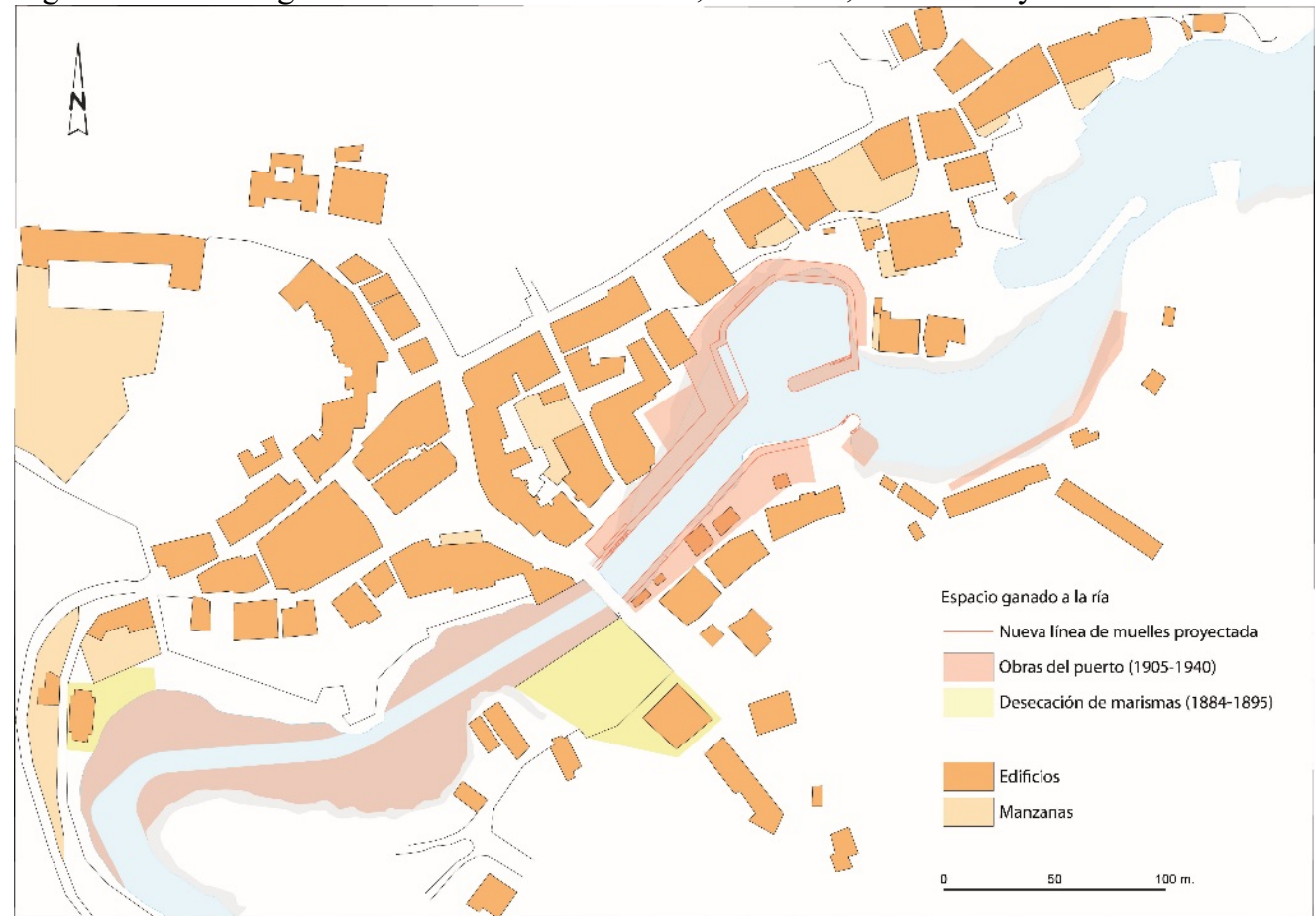

Fuente: Elaboración propia a partir del plano de 1895 de Rafael Martín y del plano de 1914 del puerto de Llanes de Toribio Quiroga.

${ }^{8}$ AHMLL, Libros de actas del concejo, libro no 30, sesión del día 09/10/1886.

${ }_{9}^{9}$ Gaceta de Madrid, no 83, 24-3-1886; no 60, 1-3-1890; Boletín Oficial de la Provincia de Oviedo, 2511-1897.

${ }^{10}$ AHMLL. Libros de actas del concejo, libro n ${ }^{\circ} 29$, sesión del día 29/03/1884, libro nº 36, sesión del día 02/06/1900 y libro $n^{\circ} 39$, sesión del día 23/01/1904. 
Las obras realizadas en Ribadesella para mejorar las instalaciones portuarias fueron de mucha mayor envergadura que en Llanes, por lo que también contribuyeron en mayor medida a la obtención de terrenos en los que construir el espacio burgués. Más aun debido a las condiciones de su emplazamiento, en una estrecha franja de tierra limitada por la línea de costa y las faldas del monte Corbero y el cerro de La Cuesta, que prácticamente impedían la expansión urbana en cualquier dirección que no fuese la del mar.

Figura 2. Terrenos ganados a la ría del Sella, en Ribadesella, con las obras realizadas en el puerto entre 1784 y 1960.

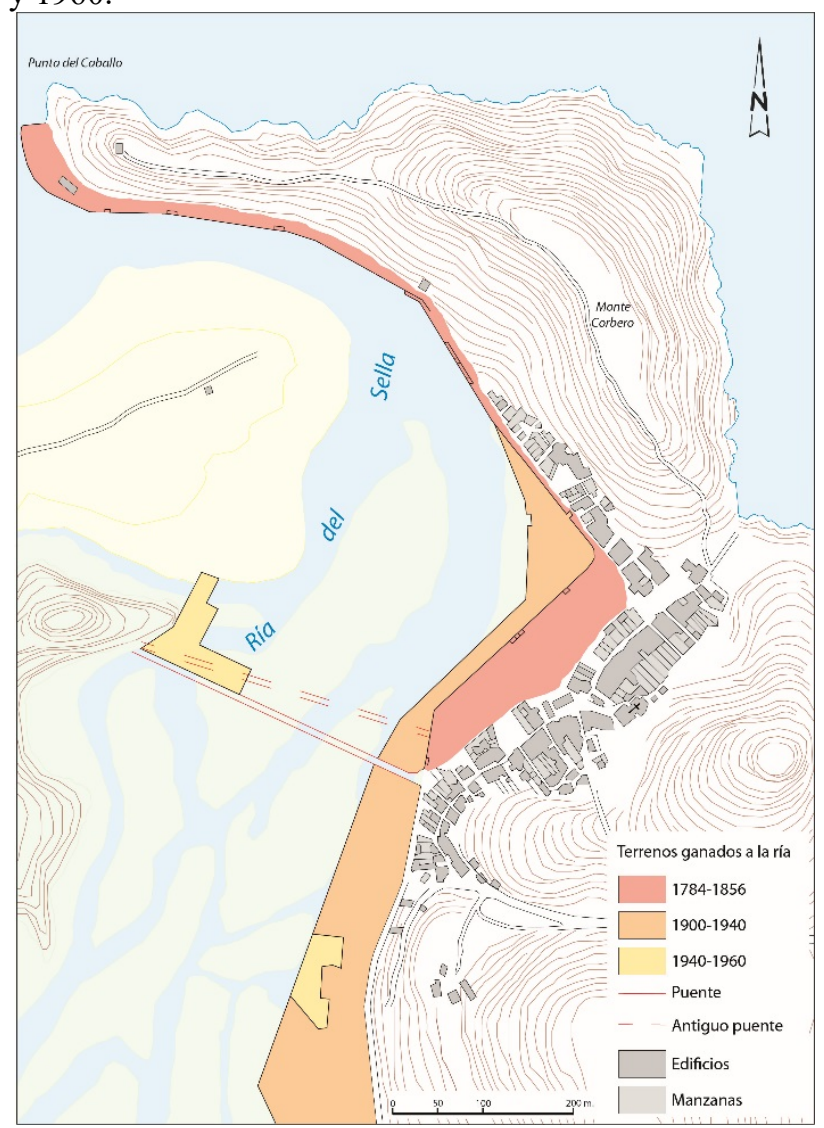

Fuente: elaboración propia a partir de los planos de Francisco Coello (1870), Pedro Ruidavets (1878) y el de 1940 incluido en AGPA, y el de 1955 incluido en AMR, así como de la fotografía aéreas del año 1945, del vuelo americano Serie A.

A partir de 1784 (Pérez, 2009a), para ampliar la superficie de los muelles y profundizar sus calados, comenzaron a construirse nuevos diques de contención aguas adentro, a una distancia de entre 80 y 110 metros de la antigua línea de costa. Una vez 
terminados estos, y concluidas también las posteriores tareas de desecación y relleno, la localidad dispuso de una gran explanada frente al mar sobre la que poder expandirse. El propio proyecto de mejora de los muelles, de D. Miguel de la Puente, ya incluía una propuesta de alineaciones para ocupar esa explanada (Adaro, 1979) que, sin embargo, no prosperó. Finalmente, la ocupación de este espacio se hizo conforme al proyecto encargado por el consistorio al arquitecto e ingeniero Darío de Regoyos, que fue quien definió la trama que todavía persiste ${ }^{11}$, sobre la que se levanta la mayor parte de los edificios promovidos en la villa durante las décadas finales del siglo XIX y las primeras del XX (Fig. 2) .

Pero no fueron estas las únicas obras que permitieron a Ribadesella ganar terreno al mar, también lo hicieron otras realizadas durante las cuatro primeras décadas del siglo XX. Las acometidas aguas abajo del puente de hierro, inaugurado en 1898, adelantaron aún más la anterior línea de atraque de los barcos, de manera que aumentaron la superficie de los muelles, lo que permitió construir en ellos algunos edificios municipales, como la lonja o unos urinarios públicos (Pérez, 2009b, 2010a, 2010b). Por su parte, las efectuadas aguas arriba del puente, con el fin de canalizar las márgenes de la ría, permitieron desecar y rellenar amplios sectores marismeños y obtener así extensos baldíos. El ayuntamiento diseñó, entonces, varios proyectos para levantar sobre ellos edificios de viviendas, equipamientos y zonas verdes, pero su ocupación fue muy lenta hasta después de la Guerra Civil (Pérez, 2009b, 2010a, 2010b).

\subsection{El papel desempeñado por los "indianos" en la construcción del espacio burgués}

Otro rasgo común a Llanes y Ribadesella, también presente en otras villas, fue el papel desempeñado por los "indianos", una estirpe de emigrantes al continente americano, rica y muchas veces retornada, que tuvo un gran influjo en la sociedad y en la economía de ambas localidades durante esta época. Su influencia en la renovación urbana se dejó sentir desde mediados del siglo XIX por las donaciones o suscripciones populares que realizaron para impulsar diversas mejoras urbanas, como la construcción del Paseo de San Pedro de Llanes (Pedregal, 1999). Pero su influencia aumentó a partir de los últimos años del siglo XIX, cuando el retorno de gran parte de estos emigrantes se tradujo en una intensificación de su participación en la actividad económica y en el urbanismo local. Así, de su empuje surgieron diversas iniciativas empresariales, tanto industriales como comerciales, que propiciaron el enriquecimiento de la población y estimularon el crecimiento demográfico. Además,

\footnotetext{
${ }^{11}$ Pérez, 2013, y AMR, Libros de actas del pleno, libro n ${ }^{\circ}$ 5, sesión del día 03/12/1852. El proyecto fue recibido por el consistorio en enero de 1854. Más tarde fue remitido al Gobernador de la Provincia y a la Junta Superior Consultiva de Policía Urbana del Ministerio de la Gobernación para que diesen su visto bueno, y fue definitivamente aprobado por Real Orden el 10 de febrero de 1855. AMR, Libros de actas del pleno, libro $\mathrm{n}^{\circ}$ 5, sesión del día 13/01/1854 y libro $\mathrm{n}^{\circ}$ 5, sesión del día 30/03/1855.
} 
impulsaron proyectos para organizar el crecimiento y la modernización de la trama urbana que incluían la construcción de viviendas, la apertura de novedosos establecimientos comerciales en los bajos de los edificios, la mejora de los servicios y los equipamientos, el trazado de nuevas calles e, incluso, la creación de nuevos espacios urbanos, si bien de tamaño generalmente reducido.

Así, la burguesía construyó directamente algunas edificaciones, que, como el balneario o el casino, estaban destinadas al uso y disfrute de personas de su misma clase social o tenían como finalidad la obtención de un rédito económico. Pero también levantó otros edificios para cubrir necesidades generales del conjunto de la población o de los sectores más desfavorecidos, que les proporcionaron un cierto reconocimiento social. En otros casos, los más habituales, la aportación burguesa se concretó en la financiación de obras promovidas desde el consistorio, bien adelantando el dinero necesario en forma de préstamos u obligaciones, bien cediendo generosas sumas de dinero sin ninguna contraprestación a cambio.

La creación de nuevos espacios urbanos, por su parte, tiene su origen en el interés de algunos de los vecinos más pudientes de la villa por lotificar amplias fincas de su propiedad a fin de disponer de solares sobre los que edificar su residencia, pero también para obtener un rédito económico tras la venta de las parcelas o el alquiler de los inmuebles construidos.

En Llanes estas iniciativas fueron responsables del diseño de varios espacios de residencia burguesa, como los que se formaron en el entorno de la calle Nueva, tras su apertura en los primeros años del siglo $\mathrm{XX}^{12}$, o en las inmediaciones del faro, en donde se levantó una colonia de chalets con vistas a la bocana de la ría y a la playa de Puerto Chico (Álvarez, 1989), para cuyo acceso fue abierta, hacia 1912, la actual calle Marqués de Argüelles. Pero las parcelaciones también dieron origen a barrios destinados a las clases sociales menos favorecidas, como el de Bustillo y o el de Juan Cuesta ${ }^{13}$. En ambos tipos de parcelaciones la finalidad especulativa parece encontrarse detrás de estas actuaciones, pues los nuevos espacios urbanos promovidos fueron rápidamente puestos en el mercado. Así ocurrió en los espacios de mayor calidad, como los solares generados a ambos lados de la calle Nueva o los chalets levantados junto al faro; pero también fue el caso de las parcelaciones cuyos destinatarios eran las clases más humildes, en las que se construyeron viviendas obreras con el fin de obtenr rentas a través de su arrendamiento.

\footnotetext{
${ }^{12}$ AHMLL, Libros de actas del concejo, libro $\mathrm{n}^{\circ} 37$, sesión del día 22/11/1902; libro $\mathrm{n}^{\circ} 38$, sesiones de los días 28/05/1904 y 12/11/1904.

${ }^{13}$ El primero, promovido por el indiano Ramón Bustillo en 1891, constaba de 23 viviendas, todas ellas, excepto una, de una planta de reducidas dimensiones y con corral en la parte trasera. Este conjunto fue derribado en la década de 1950 y en su solar se levantaron, a instancias del Instituto Nacional de la Vivienda, tres bloques con 68 pisos. El segundo barrio fue obra del emigrante retornado homónimo, quien en 1912 construyó, en terrenos propios situados en el Cueto, una pequeña barriada de ochos viviendas. AHMLL, Libros de actas del concejo, libro $n^{0}$ 44, sesión del día 05/01/1912; caja 484. Deslindes y rasantes; Rubín, 2001.
} 
En Ribadesella, por su parte, solo se ha podido identificar un ejemplo de parcelación particular, si bien de mucha mayor envergadura que los anteriores, la que afectó al Arenal de Santa Marina; una amplia franja de terreno arenoso extendida entre el río San Pedro y la playa de Santa Marina, que se situaba en la margen izquierda de la ría, cuya urbanización fue el origen de uno de los barrios más singulares de la villa, tanto por su tamaño como por la variedad de usos que acogió. $\mathrm{Su}$ superficie superaba a la ocupada por el caserío tradicional, incluida la de los terrenos que previamente se habían ganado al mar. A partir de mediados de la década de 1890, Federico Bernaldo de Quirós y María Josefa Argüelles, los segundos marqueses de Argüelles, lograron concentrar en sus manos buena parte de los terrenos entre el arenal y el río San Pedro, a través de diferentes concesiones otorgadas por el Estado y de la adquisición de fincas a otros terratenientes locales. Una vez adquiridos los terrenos fueron parcelados utilizando como eje director la escasa red viaria preexistente. Una parte de las parcelas fue utilizada para construir viviendas para veraneantes y otra, vendida. Además, aunque la mayor parte del suelo se destinó a usos residenciales (viviendas unifamiliares de grandes dimensiones sobre amplias parcelas para burgueses residentes en otras localidades asturianas o, sobre todo, de fuera de la región), también existió un aprovechamiento industrial, centrado en la rama agroalimentaria, y algunos equipamientos, sobre todo tras la instalación de un balneario que incrementó el atractivo turístico de la playa (Álvarez, 1995).

\subsection{El temprano interés de las corporaciones municipales por aprobar proyectos de ordenación urbana: los proyectos de ensanche y reforma interior}

Llanes y Ribadesella dispusieron de proyectos de transformación y expansión urbana en fecha relativamente temprana; en cualquier caso, antes que la mayoría de las villas asturianas. Ahora bien, su legado fue dispar. En el caso de la reforma interior la herencia de esos proyectos fue escasa, sin embargo la de los proyectos de ensanche fue mucho mayor, sobre todo en el caso de Ribadesella ${ }^{14}$.

En esta última villa, el ya citado proyecto de Darío de Regoyos fue aprobado en 1855, años antes, incluso, de que lo fuera la primera Ley de Ensanche. El arquitecto vallisoletano diseñó, para ocupar este espacio, una trama ortogonal compuesta por tres largos viales trazados en paralelo al muelle Sur y cuatro calles perpendiculares de menor longitud, que formarían diez nuevas manzanas. Para los terrenos colindantes con el muelle Norte, únicamente previó la alineación de una de las manzanas existentes (Fig. 3).

\footnotetext{
${ }^{14}$ En Ribadesella cabe destacar también el proyecto del arquitecto Joaquín Ortiz para el sector nororiental, que modificaba el viario en el entorno del mercado de ganados y el ensanchamiento del tramo inicial de la carretera de la estación. AMR, expediente 433.1 Construcción de un edificio de tres plantas entre la calle General Aranda y la carretera general.
} 
Figura 3. Plano del proyecto de ensanche para la villa de Ribadesella elaborado por Darío de Regoyos en $1854^{15}$.

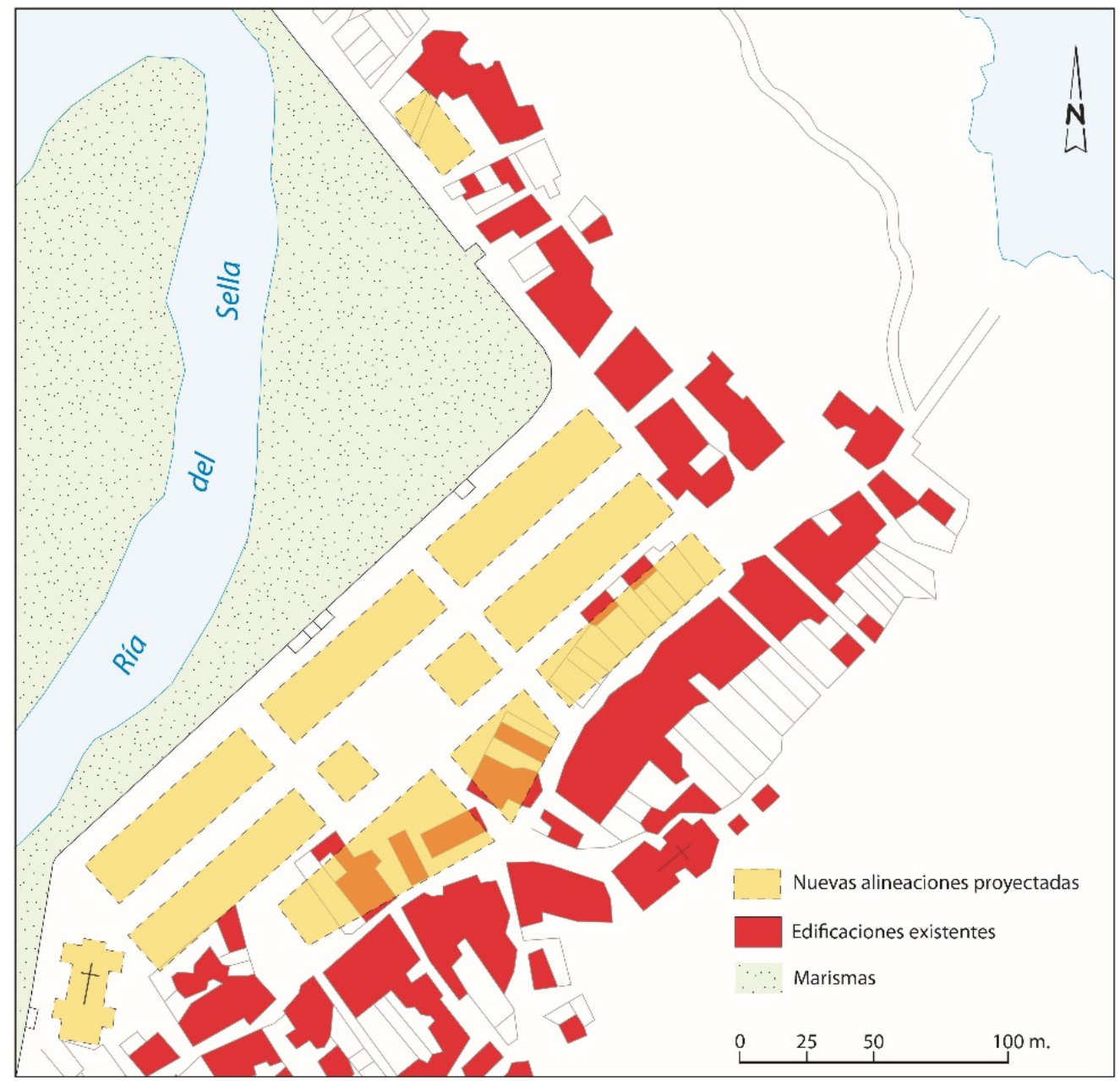

Fuente: elaboración propia a partir del plano de Francisco de Coello (1870).

En Llanes los proyectos de ensanche fueron más tardíos que en Ribadesella. El primero de ellos estuvo a disposición del ayuntamiento en 1886. Estaba firmado por

\footnotetext{
${ }^{15}$ Si bien no se conserva la cartografía original elaborada por Regoyos, el plano de Coello (1870) de la población riosellana incorpora una representación de dicho proyecto, heredero en buena medida de la fallida población ideada por Miguel de la Puente.
} 
el arquitecto e ingeniero Tomás Álvarez Diez Morán y en él se fijaban las directrices de la futura expansión urbana (que utilizaría la carretera Oviedo-Torrelavega como principal eje director) y las nuevas alineaciones para el casco antiguo, pero este documento nunca llegó a entrar en vigor. Su autor lo retiró antes de recibir la aprobación definitiva debido a la fuerte oposición que recibió durante la fase de exposición pública (Rato y Fernández, 2018).

Tuvieron que transcurrir 19 años, hasta 1905, para que el gobierno local aprobara el nuevo y ambicioso proyecto de ensanche y reforma interior que le había sido encargado al burgalés Alberto Corral (Rato y Fernández, 2018). Este ingeniero diseñó una trama muy extensa, que implicaba la apertura de 44 calles y más de 80 manzanas, con la que pretendía dotar a la villa de dos amplias zonas de expansión futuras, una a cada lado de la ría del Carrocedo, pero además rectificar el trazado de las calles preexistentes para hacerlas más anchas y rectilíneas, lo que implicaba, de hecho, una profunda transformación del casco histórico (Fig 4). El espacio de expansión del norte de la ría se situaba al oeste de la calle $\mathrm{n}^{\circ} 9$ y se caracterizaba por su plano ortogonal, solo alterado por una parte del trazado de las calles 8 y 10, que estaba adaptado a la dirección de la de antigua carretera de Oviedo. En el ámbito del casco histórico, la obra más destacada sería el ensanchamiento y realineación de la calle Mayor y del entorno de la iglesia, que pasaría a ocupar el centro de una amplia plaza rectangular, así como la apertura de otras dos plazas de menor tamaño.

Al sur de la ría, el nuevo plano se extendería siguiendo una trama muy regular, articulada por la carretera de Torrelavega, a partir de la cual se abrirían varias calles paralelas y perpendiculares a ambas márgenes, algunas de las cuales implicaban una transformación radical del viario existente, como ocurría en el barrio de El Cueto. La excepción en este caso la encontramos en el nordeste, en donde la expansión estaba condicionada por la línea de costa y por las elevaciones del alto de la Guía. Por esa razón, Alberto Corral se limitó a plantear la apertura de tres calles en el entorno de San Antón, así como a rectificar las alineaciones de algunos viejos caminos.

A estos dos proyectos de reforma y ensanche de la población les sucedió un tercer plan de estas características, limitado al entorno de la playa del Sablón, elaborado por el arquitecto municipal Joaquín Ortiz en 1930. ${ }^{16}$

\footnotetext{
${ }^{16}$ Del Río, 2011; AHMLL, Libros de actas del concejo, libro $\mathrm{n}^{\circ}$ 56, sesión del día 28/04/1930,
} 18/11/1930 y 09/03/1931; caja 106. Expedientes de subasta de obras de alcantarillado (1930). 
Figura 4. Plano del Proyecto de reforma y ensanche de la villa de Llanes de Alberto Corral (1905).

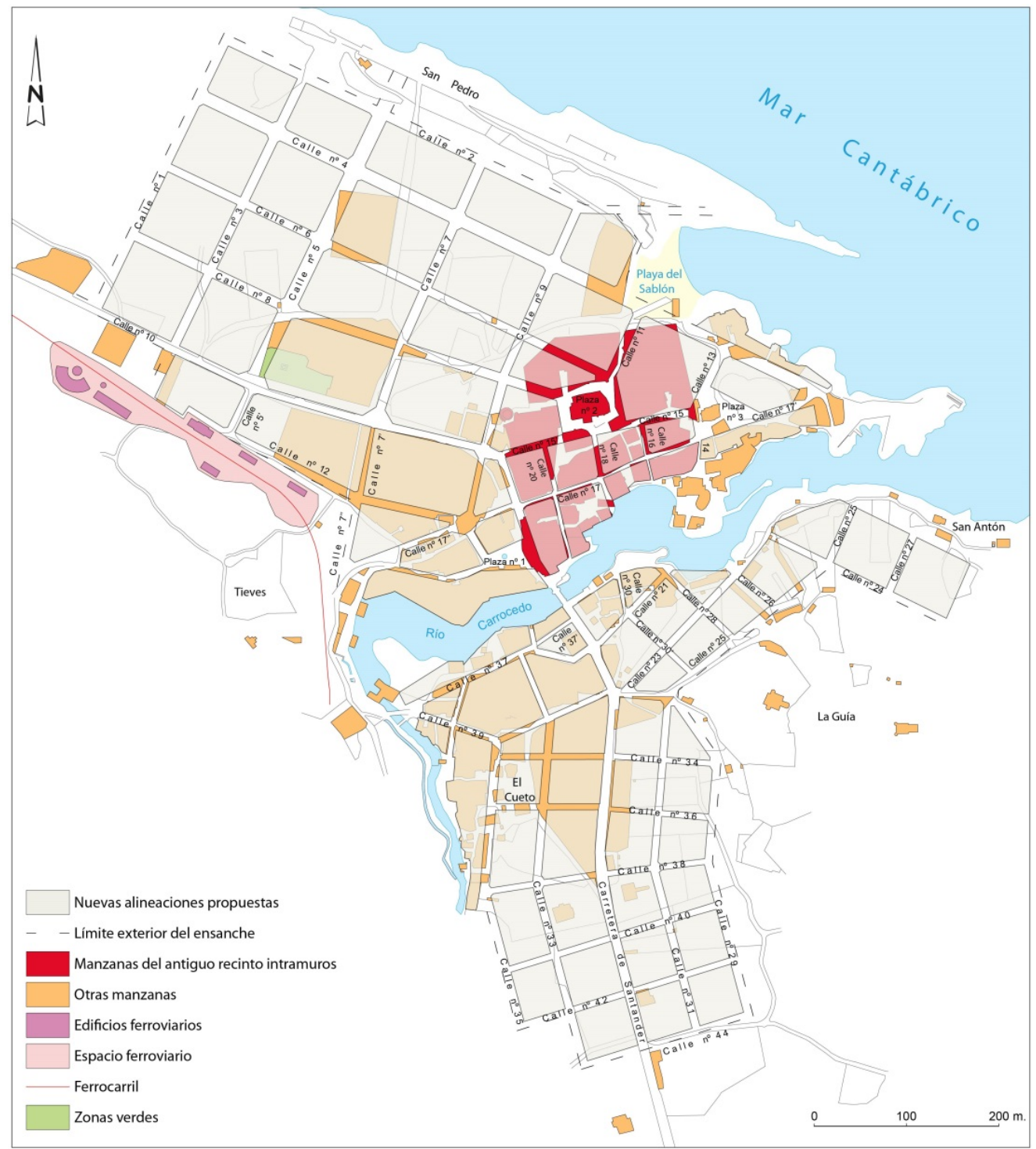

Fuente: Elaboración propia a partir del Plano de la villa de Llanes levantando por el Ingeniero de Caminos, Canales y Puertos D. Alberto Corral. Año 1902 (Ayuntamiento de Llanes) y del Plano general de Llanes. Mayo 1905. (AMRV). 
Mayor premura presentó la primera obra de reforma interior ejecutada en la población llanisca, el proyecto de derribo del arco de la puerta de la villa de 1844, con el que se puede dar por iniciada la transformación de la ciudad del Antiguo Régimen ${ }^{17}$.

\subsection{Los rasgos diferenciadores de los espacios burgueses de Llanes y Ribadesella}

Pese a las similitudes ya expuestas, relativas fundamentalmente a las causas o a los agentes que intervinieron en su formación, los espacios burgueses de Llanes y Ribadesella poseen algunas características bien distintas emanadas, en este caso, del distinto grado de cumplimiento con el que se ejecutaron los diferentes planes urbanísticos aprobados por sus respectivas corporaciones municipales.

En el ámbito de la reforma interior, las principales diferencias estribaron en la forma en la que se abordó el engarce entre el casco histórico y los barrios nuevos. En Ribadesella se resolvió mediante una actuación relativamente sencilla, consistente en rectificar la alineación del antiguo frente marítimo para adecuarlo a la trama del ensanche, lo que permitió abrir la actual calle de la Gran Vía ${ }^{18}$ (Fig. 5). En Llanes, por su parte, el procedimiento seguido fue más complejo, pues tuvo que solventar el problema que representaba la pervivencia de su muralla medieval. Para solucionarlo no nos consta que se planteara el derribo total de la cerca, probablemente por su elevado coste o por considerar que no era necesaria una operación urbanística de tal enjundia, toda vez que la villa había iniciado su crecimiento fuera del recinto intramuros siglos atrás ${ }^{19}$; se consiguió sencillamente eliminando las principales puertas de acceso, como las de la Villa, San Nicolás, Llegar o del Castillo (Álvarez, 2012), que dificultaban la circulación por algunas de las calles más transitadas.

Por lo que respecta a la forma en la que fue absorbido el crecimiento de la población las diferencias también fueron notables. En Llanes se realizó en gran medida ocupando los baldíos existentes en los barrios históricos, especialmente en los arrabales, en los que la mayor disponibilidad de suelo había permitido una ocupación tradicional menos densa. Además, cuando lo hizo hacia el exterior, lejos de adaptarse a los nuevos viales que deberían abrirse al amparo del planeamiento vigente, utilizó como eje director la carretera de Oviedo a Torrelavega, en cuyas márgenes se levantaron a partir de la década de 1860 varias viviendas burguesas (Fig. 6). Paradójicamente, dichas edificaciones terminaron por otorgar a esta parte de la ciudad el aspecto burgués buscado por el plan de ensanche que, sin embargo, había sido ignorado.

\footnotetext{
${ }^{17}$ AHMLL, caja 480. Expediente de demolición del arco de la Puerta de la Villa (1844-1845) y Libros de actas del concejo, libro $\mathrm{n}^{\circ}$ 14, sesión del día 4/11/1845.

${ }^{18}$ AMR, caja 319, "Expediente sobre el ensanche de la Calle de ésta Villa La Gran Vía”; Libros de actas del pleno, libro $\mathrm{n}^{\circ} 12.7$, acuerdos de los días 23-3-1892, 11-5-1892, 13-7-1892 y 31-8-1892.

${ }^{19}$ En Llanes es bien conocida la existencia de dos barrios extramuros en la época medieval, uno frente a las puerta del Este y el otro frente a la del Oeste, es decir allí donde el medio físico ponía menos restricciones a la expansión urbana.
} 
Figura 5. Vista de la Gran Vía de Ribadesella en $1915^{20}$.

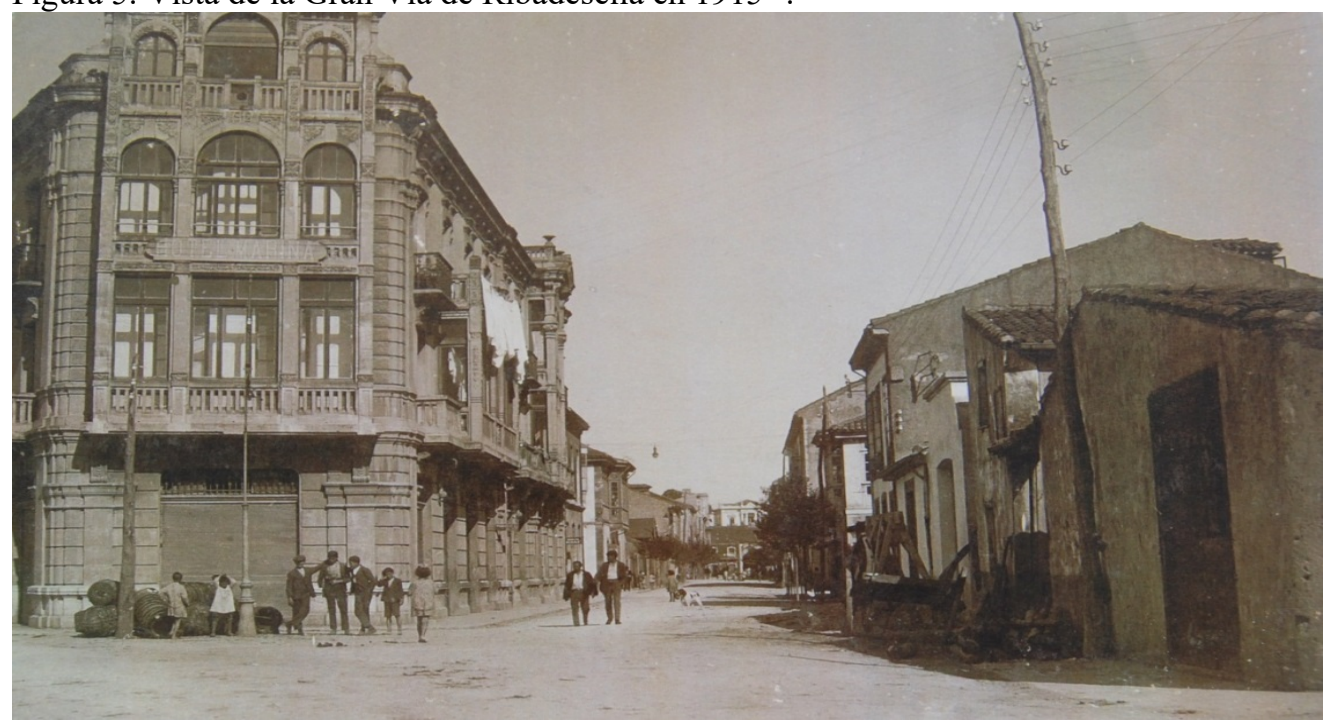

Fuente: Fotografía procedente del Archivo Municipal de Ribadesella.

Figura 6. Las márgenes de la carretera de Oviedo a Torrelavega ${ }^{21}$.

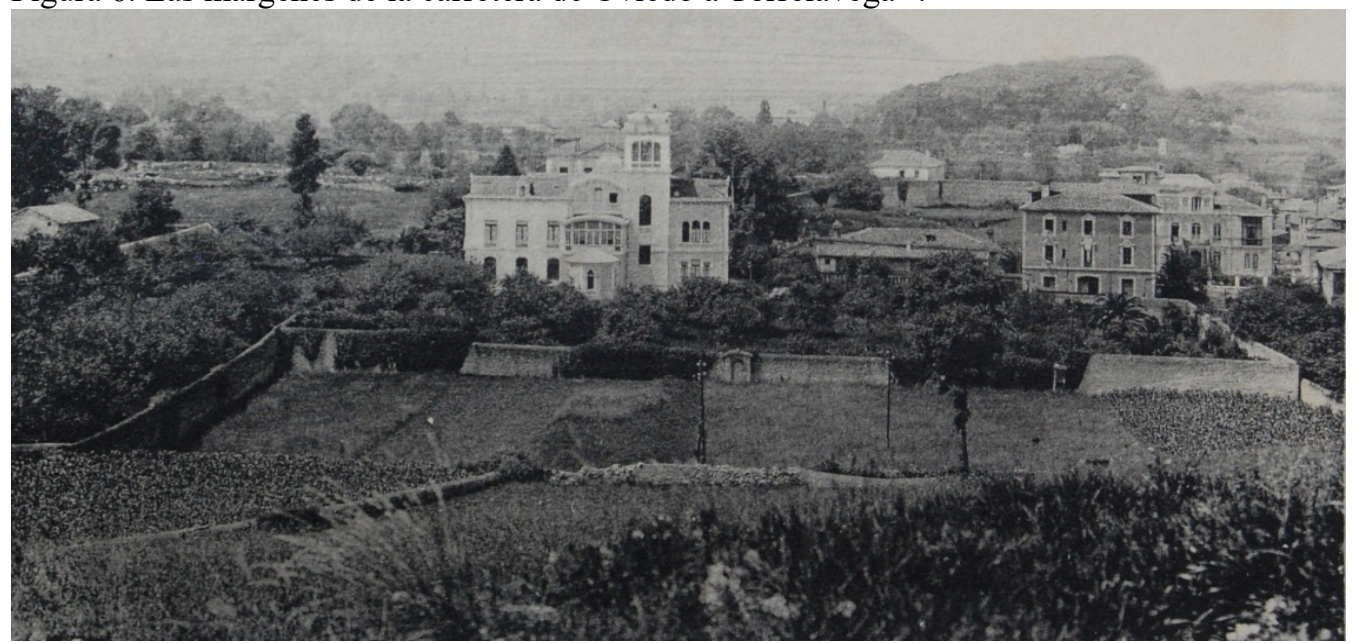

Fuente: Fotografía procedente de la fototeca del Oriente de Asturias, AHMLL.

${ }^{20}$ La calle fue abierta entre 1892 y 1912 para servir de engarce entre el casco histórico y el ensanche levantado sobre los terrenos ganados al mar con las obras de ampliación del puerto.

${ }^{21}$ fueron el espacio seleccionado por la burguesía llanisca para levantar sus residencias. La gran disponibilidad de espacio en las zonas más alejadas del centro de la localidad permitió levantar viviendas de grandes dimensiones sobre parcelas igualmente de gran tamaño. 
Figura 7. La herencia de la ciudad histórica y de la ciudad burguesa en Ribadesella en 1960.

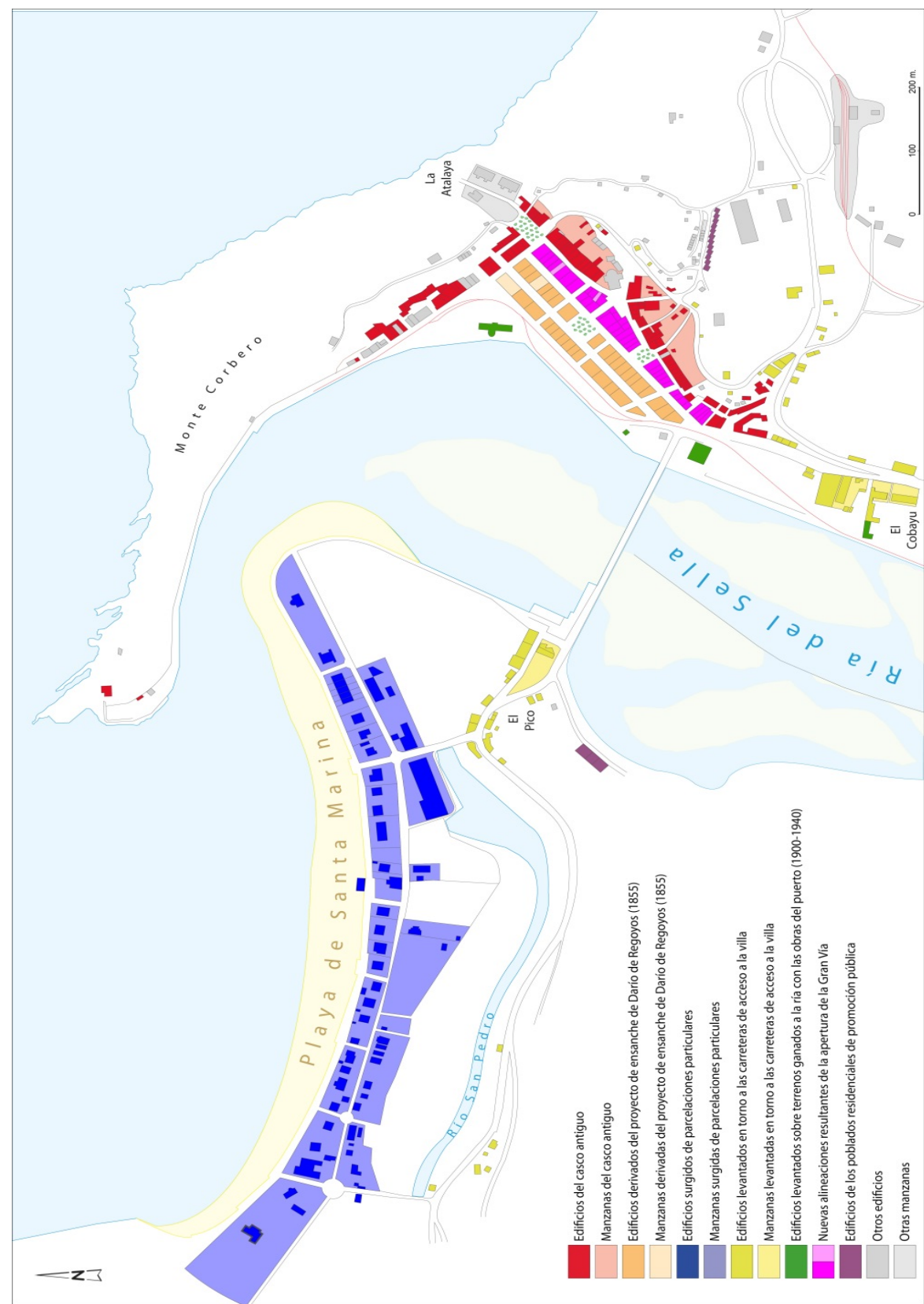

Fuente: elaboración propia a partir del plano de Ribadesella de 1955 incluido en AMR, del Catastro fotográfico (años 1956-1958) y de la fotografía de CECAF de 1963. 
Figura 8. La herencia de la ciudad histórica y de la ciudad burguesa en Llanes en 1960.

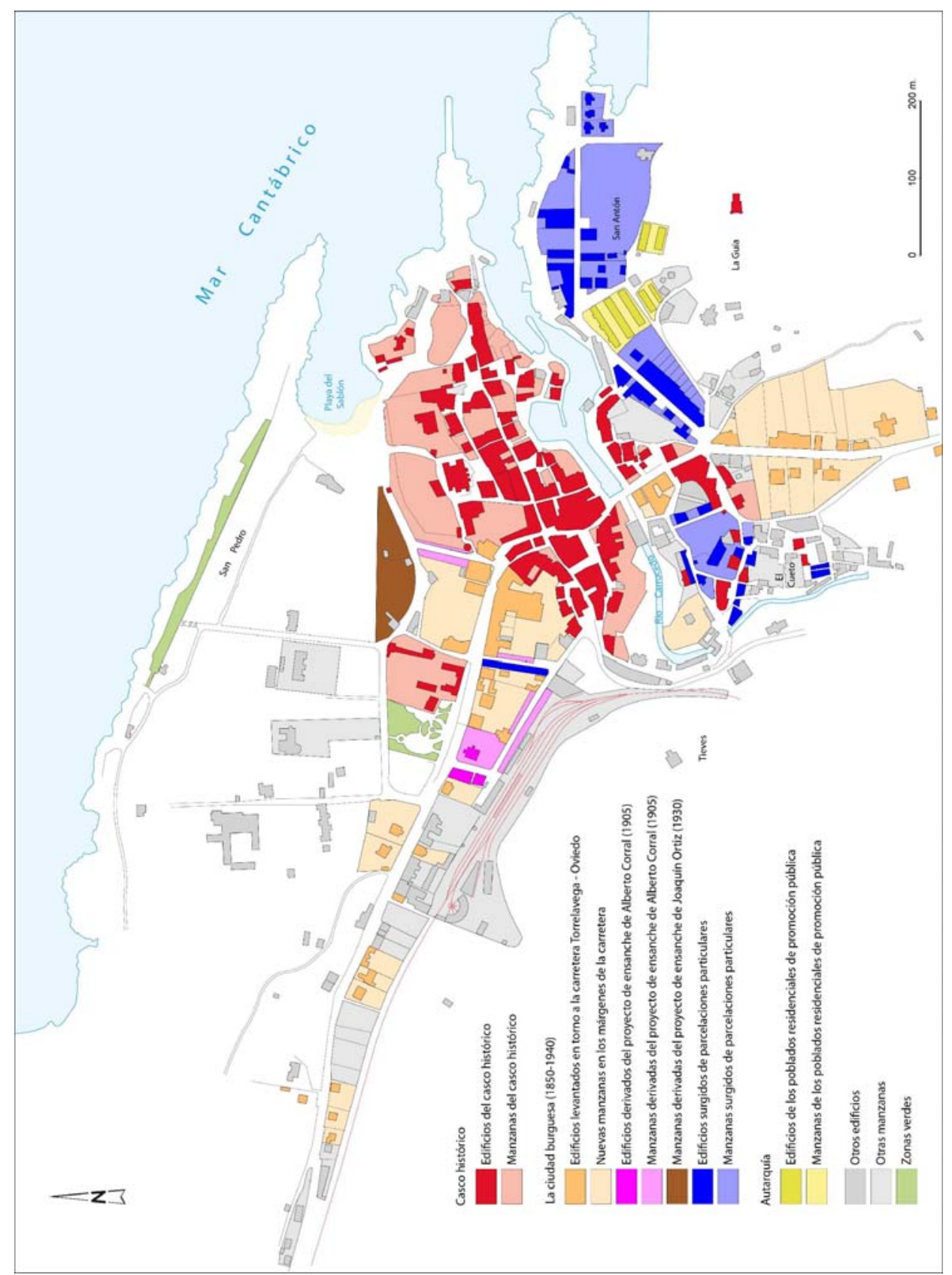

Fuente: elaboración propia a partir del plano de Llanes de 1955 de Juan Ortega, del Catastro fotográfico (años 1956-1958) y de la fotografía de CECAF de 1963. 
En Ribadesella la absorción en el interior del casco histórico fue mucho menos intensa a causa de su elevada densidad edificatoria, y el relleno de los baldíos existentes se redujo a la construcción de un escaso número de viviendas en los barrios del Portiello y de Santa Ana. En consecuencia, la localidad se vio obligada a expandirse, pero, a diferencia de lo ocurrido en la villa llanisca, el escaso espacio llano disponible en las márgenes de las carreteras limitó su uso como ejes directores del crecimiento, salvo en parajes concretos como El Pico o El Cobayo. Por tanto, aquélla se realizó casi siempre mediante la creación de nuevos barrios, cuya trama siguió las directrices marcadas por el planeamiento municipal o por la iniciativa privada (Fig. 7).

El legado dejado por los proyectos de ensanche también ha sido desigual en las dos villas. La trama diseñada por Darío de Regoyos para ocupar los terrenos ganados al mar es todavía fácilmente identificable en el plano de Ribadesella, merced a la fidelidad al proyecto original con la que se produjo la ocupación de este espacio. El proceso arrancó en 1873, una vez que desde el gobierno central se autorizó a la subasta de los solares de la nueva población ${ }^{22}$, y en pocas décadas se colmataron la práctica totalidad de las parcelas. Debido a la disponibilidad de espacio libre y a las buenas condiciones de salubridad, este espacio fue elegido por la burguesía como lugar predilecto de residencia.

En Llanes, sin embargo, pese a haber contado con tres proyectos de ensanche su herencia ha sido mucho menor, puede decirse que testimonial (Fig. 8). Sus excesivas dimensiones, muy superiores a las demandadas por su crecimiento demográfico, y la oposición de los propietarios de los terrenos afectados, redundaron en su escasa efectividad (Rato y Fernández, 2018). Con anterioridad a la Guerra Civil solo cabe señalar la apertura de dos calles y la alineación de otra en el entorno de la estación ${ }^{23}$, y con posterioridad a ella la de la calle actual de Alfonso IX, abierta entre 1945 y 1956, a fin de mejorar la circulación entre el centro y la playa del Sablón y su entorno, uno de los espacios, presumiblemente, con mayor proyección futura ${ }^{24}$.

\section{Conclusiones}

El proceso de modernización urbana, iniciado a mediados del siglo XIX y prolongado hasta el estallido de la Guerra Civil, no solo afectó a las principales ciudades del país, también se trasladó a los niveles más bajos de la jerarquía urbana, de manera que, todavía hoy, son visibles en muchas villas y otras pequeñas ciudades piezas urbanas

\footnotetext{
22 Álvarez, 1995; AMR, Libros de actas del pleno, libro $\mathrm{n}^{\circ}$ 9.7, acuerdos de los días 24/08/1873, $01 / 10 / 1873$ y $01 / 10 / 1873$.

${ }^{23}$ Estas mejoras estuvieron impulsadas por la construcción de la estación, en 1905, y por la inauguración de la carretera a Meré, a mediados de la década siguiente.

${ }^{24}$ AMLL, Libros de actas del pleno, libro 7558.1, sesiones de los días 14/05/1945 y 23/05/1946; libro 4078.2, sesión del día 28/07/1956.
} 
construidas durante aquella época. Piezas típicas del modelo urbano burgués, como los ensanches, las parcelaciones particulares o las tramas regulares resultantes de actuaciones de reforma interior.

Parece lógico que así sea, pues las causas que impulsaron aquella modernización, fundamentalmente la llegada las primeras manifestaciones de la revolución industrial y sus principales secuelas (crecimiento demográfico, aumento de la riqueza, nuevos medios de transporte, transformación de la sociedad, etc.), también afectaron a estas localidades menores, aunque fuera con menor intensidad. Por ello las transformaciones que provocaron fueron de menor envergadura. Además, no podemos obviar la importancia que tuvieron en ese proceso de transformación algunos fenómenos de carácter local, sin cuya impronta no podrían explicarse ciertos rasgos particulares del espacio burgués de estas pequeñas ciudades.

En las dos villas asturianas analizadas en este artículo, esas causas de carácter local, al igual que la generales, fueron muy similares. Su localización en la desembocadura de un río (aprovechada por los consistorios y por la iniciativa particular para la obtención de terrenos llanos), el protagonismo de la burguesía local (sobre todo ligada al continente americano), y la voluntad municipal por promover diversas obras públicas ya desde época temprana son rasgos comunes a ambas localidades

Pese a ello, los dos espacios burgueses generados poseen sus propias características distintivas, pues el grado de aplicación de la normativa urbanística vigente en cada época no ha sido siempre el mismo. Así, en Llanes, la existencia de una muralla dificultó la realización de obras de reforma interior y, por el contrario, la proliferación de espacios libres en la trama heredada facilitó que esta absorbiera una parte del crecimiento. En Ribadesella, sin embargo, las obras del puerto proporcionaron a la villa una amplia superficie de suelo urbano que fue aprovechada para el diseño y ocupación de un nuevo barrio de trama regular; al otro lado de la ría, la iniciativa privada impulsó la urbanización de los extensos baldíos situados junto al arenal de Santa Marina.

A partir de los años 60, tanto Llanes como Ribadesella han experimentado cambios sustanciales en los espacios urbanos creados durante las décadas anteriores. Cambios que, al estar amparados en una pujante actividad turística, han cristalizado tanto en la fuerte expansión del plano como en el cambio de uso experimentado por algunos de los más significativos edificios levantados por la burguesía. Así, algunos de los edificios aparecidos entre mediados del siglo XIX y principios del XX están dedicados hoy en día a la satisfacción de la demanda turística, después de haber sido transformados en hoteles o utilizados sus bajos para actividades de restauración.

\section{Bibliografía}

Acevedo y Huelves, B. (1900): Navia y Villayón. En O. Bellmunt y F. Canella. Asturias. T. III, 326-332. 
Adaro Ruiz-Falcó, L. (1979): El puerto de Gijón y otros puertos asturianos, Vol. 2, Gijón, Cámara Oficial de Comercio, Industria y Navegación.

Álvarez Carballo, M. (2012): Arquitectura y ciudad. Urbanismo medieval en Asturias: Llanes, Oviedo, Universidad de Oviedo (Tesis doctoral inédita).

Álvarez Quintana, C. (1989): Los chalets de San Antón y el primer lanzamiento turístico de Llanes. El Oriente de Asturias, número extraordinario de junio, 31-35.

Álvarez Quintana, C. (1995): Baños de mar en Ribadesella 1890-1936. Urbanismo, arquitectura y sociedad. Ribadesella, Asociación Cultural Amigos de Ribadesella.

Alvargonzález Rodríguez, R. M. (1977): Gijón: industrialización y crecimiento urbano, Salinas, Ayalga.

Bassols Coma, M (1973): Génesis y evolución del derecho urbanístico español: (1812-1956), Madrid, Montecorvo.

Capel Sáez, H. (1975): Capitalismo y morfología urbana en España. Barcelona, Los Libros de la Frontera.

Delgado Viñas, C. (1995): Las pequeñas y medianas capitales de provincia en el proceso de modernización del sistema urbano español. Las Palmas, Universidad de Las Palmas de Gran Canaria, Servicio de Publicaciones.

Erice Sebares, F. (1994): Nacimiento y consolidación de la burguesía industrial. En Ojeda Gutiérrez, G. y Vázquez García, J. A. (Coord.). Historia de la economía asturiana, Vol 2, Oviedo, Prensa Asturiana, 289-304

Esteban i Noguera, J. (1976): Los ensanches menores en la región de Barcelona (II). Barcelona, Laboratori d'urbanisme de Barcelona.

Fernández Cuesta, G. (2002): El marco geográfico. En El libro de Siero, Pola de Siero, Patronato Municipal de Cultura de Siero, 15-74.

Fernández Cuesta, G. (2011): Crecimiento urbano y modernización en España entre 1857 y 1900. Ería: Revista cuatrimestral de geografía, 84-85, 5-46.

Fernández Cuesta, G. (2015): Urbe II: la construcción histórica de la ciudad de Gijón. Oviedo. Ediciones de la Universidad de Oviedo.

Fernández García, A. (1980): Langreo, industria, población y desarrollo urbano. Oviedo, Universidad de Oviedo, Facultad de Letras.

Fernández García, A. (1982a): Las ciudades mineras: Langreo y Mieres. En Quirós Linares, F. (Dir.). Geografía de Asturias, Vol. 2. Salinas, Ayalga, 15-21.

Fernández García, A. (1982b): Langreo. En Quirós Linares, F. (Dir.). Geografía de Asturias, Vol. 2. Salinas, Ayalga, 23-73.

Fernández García, A. y Velasco Rozada, J. (1992): El valle de Langreo: Langreo y San Martín del Rey Aurelio. En Morales Matos, G. (Dir). Geografía de Asturias, Vol. 4, Oviedo, Prensa Asturiana, 93-112.

Fernández de Miranda, A. (1982): Grado y su concejo. Oviedo, Imprenta Provincial.

Fernández Prieto, J. R. y Fernández Cuesta, G. (1991): El sistema urbano asturiano. Ería: Revista cuatrimestral de geografía, 26, 217-228.

García Álvarez, D. (2013): Análisis geográfico del crecimiento espacial de la villa de Pravia. Oviedo, Universidad de Oviedo, Trabajo de Fin de Grado inédito.

Gobierno Civil de la Provincia (1897): Boletín Oficial de la Provincia de Oviedo, 272, $25 / 11 / 1897$ 
López Fernández, B. (1992): La población de Asturias: evolución, reparto espacial y caracteres estructurales. En Morales Matos, G. (Dir). Geografía de Asturias, Vol. 1, Oviedo, Prensa Asturiana, 81-96.

Martínez Fernández, J. (1965): Navia remota y actual. Datos y referencias para su historia. Siglo XIX: el final de un letargo. Boletín del Instituto de Estudios Asturianos, 56, 135-196.

Mas Hernández, R. (1996): La promoción inmueble en España (1846-1995). Ciudad y territorio: Estudios territoriales, 107-108, 241-269.

Mas Hernández, R. (1999): La promoción inmobiliaria en los ensanches del siglo XIX. Ciudad y territorio: Estudios territoriales, 119-120, 55-73.

Méndez García, B. (1993): La marina occidental asturiana. Vilassar de Mar, Oikos-Tau.

Ministerio de Fomento (1886): Real orden desestimando la petición del Ayuntamiento de Llanes, y á su vez otorgar á D. Agapito Fernández, D. Bruno García y D. Juan Sordo, vecinos de dicha villa, la concesión solicitada por los mismos para sanear los terrenos ó marismas denominados El Hospital. Gaceta de Madrid, 83, 24/03/1886, 907.

Ministerio de Fomento (1890): Real orden otorgando á D. Juan García Varela el trozo de marisma comprendido entre el puente sobre el río Melendre de la carretera de Torrelavega á Oviedo, la casa del Sr. Nachón y una parcela de la propiedad del solicitante. Gaceta de Madrid, 60, 01/03/1890, 620.

Morales Matos, G. (1983): Avilés. En Quirós Linares, F. (Dir.). Geografía de Asturias, Vol. 3, Salinas, Ayalga, 5-87.

Murcia Navarro, E. (1981): Las villas costeras en el sistema urbano asturiano, Gijón, Silverio Cañada.

Murcia Navarro, E. (1983): Los centros comarcales. En Quirós Linares, F. (Dir.). Geografía de Asturias, Vol. 3, Salinas, Ayalga, 177-248.

Pedrayes Obaya, J. J. (1994): Villaviciosa de Asturias, análisis urbano, Oviedo, Colegio Oficial de Arquitectos de Asturias.

Pedregal Galguera, V. (1999): Glosas a la historia de Llanes. Llanes, El Oriente de Asturias.

Pérez González, R. (1982): Mieres. En Quirós Linares, F. (Dir.). Geografía de Asturias, Vol. 2. Salinas, Ayalga, 75-136.

Pérez González, R., Fernández García, F. y Morales Matos, G. (1983): La población y el poblamiento. En Quirós Linares, F. (Dir.). Geografía de Asturias, Vol. 4. Salinas, Ayalga, 233-277.

Pérez Valle, J. J. (2009a): El puerto de Ribadesella (I). La Plaza Nueva, 27, 50-72.

Pérez Valle, J. J. (2009b): El puerto de Ribadesella (II) (1901-1918). La Plaza Nueva, 28, 6690.

Pérez Valle J. J. (2010a): El puerto de Ribadesella (III) (1919-1937). La Plaza Nueva, 29, 3654.

Pérez Valle, J. J. (2010b): El puerto de Ribadesella (y IV) (1938-1978)”. La Plaza Nueva, 30, 36-54.

Pérez Valle, J. J. (2013): Darío de Regoyos Molenillo y Ribadesella. La Plaza Nueva, no 36, pp. 55-65.

Pérez Valle, J. J. (2017): El puente de hierro. La Plaza Nueva, 43, 55-62.

Quirós Linares, F. (1985): El proyecto de ensanche de Pola de Siero de 1932. Ástura: Nuevos cartafueyos d'Asturies, 3, 95-96. 
Quirós Linares, F. (1983): Oviedo. En Quirós Linares, F. (Dir.). Geografía de Asturias, Vol. 3. Salinas, Ayalga, 89-175.

Rato Martín, H. y Fernández Cuesta, G. (2016): El Plano de población y ensanche de la villa de Navia de 1934. Ería: Revista cuatrimestral de geografía, 99-100, 339-350.

Rato Martín, H. y Fernández Cuesta, G. (2018): El proyecto de reforma y ensanche de la villa de Llanes de 1905. Boletín de la Asociación de Geógrafos Españoles, 76, 414-429.

Reglamentos para la ejecución del Estatuto Municipal aprobados por los Reales Decretos de 2, 10 y 14 de julio y 22 y 23 de agosto de 1924 (1924), Madrid, Reus.

Río Pérez, H. Del (2011): Joaquín Ortiz, un arquitecto racionalista. Oviedo, Hércules Astur de Ediciones.

Rodríguez Felgueroso, A. J. (1993): Retrato de un paisaje: el Alto Nalón: de los albores de la minería al ocaso de un siglo, Oviedo, Gobierno del Principado de Asturias.

Rubín De Celis, C. (2001): Recuerdos y memorias. Llanes, El Oriente de Asturias.

Suárez Antuña, F. (2000): Sotrondio transformaciones urbanas recientes en una villa de la Cuenca Hullera Central. Oviedo, Universidad de Oviedo (Memoria de licenciatura inédita)

Tomé Fernández, S. (1988): Oviedo, la formación de la ciudad burguesa, 1850-1950, Oviedo, Colegio Oficial de Arquitectos de Asturias, Oviedo.

Vázquez García, J. A.; Ojeda Gutiérrez, G. (1990): Asturias: una industrialización intervenida. En Nadal, J. y Carreras i Odriozola, A. (Coord.): Pautas regionales de la industrialización española (siglos XIX-XX). Barcelona, Ariel, 49-78.

\section{Fuentes documentales}

Archivo General de la Administración del Principado de Asturias (AGPA)

Archivo Histórico de Asturias (AHA)

Archivo Histórico Municipal de Llanes (AHMLL)

Archivo Municipal de Llanes (AMLL)

Archivo Municipal de Ribadedeva (AMRV)

Archivo Municipal de Ribadesella (AMR)

Fototeca del Departamento de Geografía de la Universidad de Oviedo 